\title{
CONFLITOS AMBIENTAIS RELACIONADOS À PESCA ARTESANAL NA ZONA COSTEIRA BRASILEIRA
}

\author{
Environmental conflicts related to \\ artisanal fisheries in the brazilian coast
}

\begin{abstract}
Juliana Conti Hübner ${ }^{1,2^{\star}}$, Kelen Rodrigues da Veiga ${ }^{1.2}$, Andrine da Silva Longaray ${ }^{1,2}$, Gracieli Trentin ${ }^{2}$, Liandra Peres Caldasso ${ }^{3}$, Márcia Borges Umpierre ${ }^{2,3}$, Tatiana Walter ${ }^{2}$

${ }^{1}$ Graduação em Gestão Ambiental, Universidade Federal do Rio Grande. 2 Instituto de Oceanografia, Laboratório Interdisciplinar de Mapeamento em Ambientes, Resistência, Sociedade e Solidariedade (Maréss), Universidade Federal do Rio Grande, São Lourenço do Sul, RS, Brasil. ${ }^{3}$ Instituto de Ciências Econômicas, Administrativas e Contábeis, Universidade Federal do Rio Grande. *Autor para correspondência: gracieli.trentin@gmail.com
\end{abstract}

\begin{abstract}
RESUMO
O trabalho teve como objetivo identificar e mapear os conflitos ambientais que abrangem a comunidade pesqueira artesanal na zona costeira brasileira, de forma a proporcionar maior visibilidade aos atores sociais, vitimizados pela desigualdade e injustiça ambiental, em favor de projetos econômicos. Para esta análise foram utilizados os dados do Mapa de Conflitos e Injustiça Ambiental em Saúde no Brasil elaborado pela Fiocruz, de forma a sistematizar uma proposta metodológica focada nos conflitos presentes nos estados costeiros do país e relacionados com a pesca artesanal. Os resultados apontam que os estados da Bahia (14), Ceará (12) e Rio de Janeiro (9) têm o maior número de conflitos na pesca. Entre as principais atividades econômicas geradoras de conflito na pesca artesanal destacam-se a indústria química e de petróleo/gás (35,62\%), os portos e estaleiros (32,88\%) predominantes nas regiões Sul e Sudeste -, o turismo $(30,14 \%)$ e as atividades pesqueiras e de carcinicultura $(24,66 \%)$ - com maior incidência nas regiões Norte e Nordeste do país.
\end{abstract}

Palavras-chave: conflitos ambientais, pesca artesanal, zona costeira, gestão ambiental, vulnerabilidade social.

\section{ABSTRACT}

This work aimed to identify and map the environmental conflicts that encompass the artisanal fishing community in the Brazilian coastal zone, in order to provide greater visibility to the social

Recebido em: $12 / 11 / 2019$

Aprovado em: 26/06/2020

Publicado em:30/01/2021 
actors victimized by environmental inequality and injustice in favor of economic projects. For this analysis data from the Map of Conflicts and Environmental Injustice in Health in Brazil elaborated by Fiocruz were used, in order to systematize a methodological proposal focused on the conflicts present in the coastal states of the country and related to artisanal fishing. The results indicate the states of Bahia (14), Ceará (12) and Rio de Janeiro (9) to be the ones with the largest number of fishing related conflicts. Among the main economic activities that generate conflict in artisanal fishing are the chemical and oil/gas industry $(35,62 \%)$, ports and shipyards $(32,88 \%)$ - predominant in the south and southeastern regions -, tourism (30,14\%) and fishing and shrimp farming activities $(24.66 \%)$ - with higher incidence in the north and northeastern regions of the country.

Keywords: environmental conflicts, artisanal fishing, coastal zone, environmental management, social vulnerability.

\section{INTRODUÇÃO}

Os conflitos ambientais envolvem grupos sociais com diferentes modos de apropriação, uso e significado de território e são originados por impactos indesejáveis, que ameaçam a continuidade das atividades desses grupos (Acselrad, 2004). Pesquisas envolvendo conflitos ambientais contribuem para a compreensão acerca da apropriação e do acesso aos recursos naturais, bem como dos processos que envolvem injustiça social (Walter et al., 2019). Essa injustiça social possui relação com a distribuição desigual do ônus e do bônus do meio ambiente, ou seja, do poder sobre a utilização dos recursos naturais. Assim, embora o desenvolvimento seja exposto como benéfico para todos - empreendedor, governo e povo -, desconsidera-se o ponto de vista da comunidade atingida, prevalecendo quase sempre a cultura desenvolvimentista (Acselrad, 2014).

Nesse contexto, a zona costeira brasileira, conforme o Plano Nacional de Gerenciamento Costeiro (PNGC II) (BRASIL, 1997), apresenta uma diversidade de ambientes, sendo também alvo de grande pressão antrópica. De acordo com o Ministério do Meio Ambiente, esse cenário complexo necessita de gestão, planejamento e ordenamento de suas diferentes atividades e usos, uma vez que apresenta áreas particularmente sensíveis, concentra 23,58\% (IBGE, 2010) da população brasileira e é alvo de vetores de desenvolvimento em franco processo de expansão (Ministério do Meio Ambiente, 2020).

Conforme Cruz e Leoncio (2013), as áreas costeiras passaram por um processo de ocupação desordenada ao longo dos anos, o que trouxe consigo diferentes conflitos ambientais. A ocupação desordenada nas áreas de zona costeira é oriunda do crescimento populacional, bem como da expansão econômica. Nesse cenário, destaca-se que a implantação e o desenvolvimento de grandes empreendimentos contribuem para o acirramento dos conflitos ambientais, visto que esses empreendimentos utilizam recursos naturais de forma mais desigual do que determinados grupos sociais. Assim, é importante ressaltar que determinados grupos sociais, com destaque neste estudo para aqueles que se relacionam com a pesca artesanal, dependem desses espaços ocupados para a manutenção de seus modos de vida.

É nesses espaços disputados entre os grupos sociais dependentes e os grandes empreendimentos que se destaca a zona costeira. Walter e Anello (2012) apontam que a destituição dos meios de vida dos grupos sociais ocorre em razão das atividades econômicas e 
da própria gestão costeira que desconsidera as especificidades, tanto da zona costeira como de grupos sociais mais vulneráveis, a exemplo dos(as) pescadores(as) artesanais.

Com intuito de entender como esses conflitos ambientais se distribuem nos estados que compreendem a zona costeira brasileira, o objetivo deste trabalho foi identificar, mapear e propor uma análise para os conflitos ambientais na área com foco nos conflitos relacionados à pesca artesanal, buscando identificar as atividades geradoras desses conflitos. A importância de tal análise se dá em decorrência da manifestação dos grupos impactados por atividades econômicas e/ou políticas públicas, que deflagram o acesso desigual ao ambiente (Acselrad; Herculano \& Pádua, 2004), entre os quais estão os diversos núcleos de pescadores(as) artesanais na zona costeira (Tomáz \& Santos, 2016). Além disso, cabe destacar a relevância da presente proposta, tendo em conta a carência de mapeamentos específicos para a pesca artesanal que possam retratar e visibilizar os conflitos ambientais existentes.

\section{MATERIAIS E MÉTODOS}

Com foco em uma maior compreensão dos conflitos ambientais relacionados às atividades pesqueiras artesanais nos estados que fazem parte da zona costeira brasileira, foi realizada uma pesquisa em alguns observatórios de conflitos, como a Fundação Oswaldo Cruz (Fiocruz), o Observatório de Conflitos do Extremo Sul e o Observatório de Conflitos de Minas Gerais (Gesta MG). Este último foi consultado pela abordagem dos conflitos, embora não tenha relação direta com a zona costeira, subsidiando as análises e a organização dos dados. Após a consulta, tomaram-se por base as informações disponíveis no Mapa de Conflitos e Injustiça Ambiental em Saúde no Brasil, elaborado e disponibilizado pela Fiocruz (http://mapadeconflitos.ensp.fiocruz.br/), por ser o observatório mais completo, no sentido de conter os dados que abrangem toda a área de estudo, além de apresentar informações com maior detalhamento sobre os conflitos ambientais.

A partir do acesso e da leitura das fichas completas dos conflitos ambientais situados nos estados que abrangem a zona costeira (Plano Nacional de Gerenciamento Costeiro PNGC II, Brasil, 1997), foram selecionadas e sistematizadas as fichas relacionadas aos grupos sociais que tinham a pesca artesanal como parte do seu processo produtivo. Os grupos sociais selecionados partiram de sua autodenominação, como pescadores artesanais, marisqueiras, caiçaras, quilombolas ou outros.

Para a compilação dos dados foram destacados os atores sociais envolvidos e as atividades geradoras de injustiça ambiental a partir dos conflitos analisados. Esses itens foram subdivididos conforme o tipo de conflito apresentado em cada caso. Essa distribuição foi elaborada com base nos resultados dos conflitos destacados, considerando pescador artesanal todo aquele que utiliza a pesca para sua subsistência e, como consequência, sofre impactos e danos diretamente por meio das atividades geradoras de conflitos ambientais e políticas públicas.

Os dados foram organizados em tabela e banco de dados inseridos no Sistema de Informação Geográfica (SIG), utilizando a base cartográfica disponibilizada pelo IBGE (2016), o que permitiu análises de cunho espacial dos conflitos da zona costeira. Na análise dos conflitos ambientais, buscou-se também realizar uma leitura entre os resultados desta pesquisa, com foco na pesca artesanal, e a análise apresentada em Porto, Pacheco e Leroy (2013), que tem por base os dados apresentados no mapa de conflitos 
da Fiocruz, utilizado como suporte para a construção do banco de dados desta pesquisa (pesquisa direcionada).

Durante a construção do banco de dados, verificou-se a necessidade de inserir alterações aos itens elencados pela Fiocruz. Isso ocorreu principalmente pelo fato de haver eventos geradores de impactos na atividade pesqueira que, em geral, não eram de grande relevância para os demais casos estudados. Entre as atividades geradoras de injustiça ambiental incluídas nesta pesquisa estão o turismo e os portos e estaleiros, por exemplo. Essas atividades foram inseridas uma vez que, ao longo da leitura e análise das fichas dos conflitos, percebeu-se sua influência direta na geração de conflitos com a pesca artesanal.

\section{RESULTADOS E DISCUSSÃO}

A zona costeira brasileira abrange 17 estados (Figura 1), contemplando 512 municípios (Pirajá Júnior, 2007). Conforme estabelecido pela Lei no 7.661, de 16 de maio de 1988, a zona costeira possui aproximadamente $7.400 \mathrm{~km}$ de extensão, com largura variando entre $70 \mathrm{~km}$ e $480 \mathrm{~km}$. Essa zona abriga um mosaico de ecossistemas que possuem grande relevância ambiental, considerando a transição entre ambientes terrestres e marinhos (Brasil, 1997). Destaca-se pela sua relevância geopolítica e pela alta pressão populacional, considerando o processo histórico de ocupação, aliadas ainda à intensidade relativa às atividades econômicas que são desenvolvidas e seus impactos sobre o ambiente. Tais impactos recaem também sobre as comunidades que dependem ambientalmente dessa área, como os pescadores(as) artesanais (Walter et al., 2019).

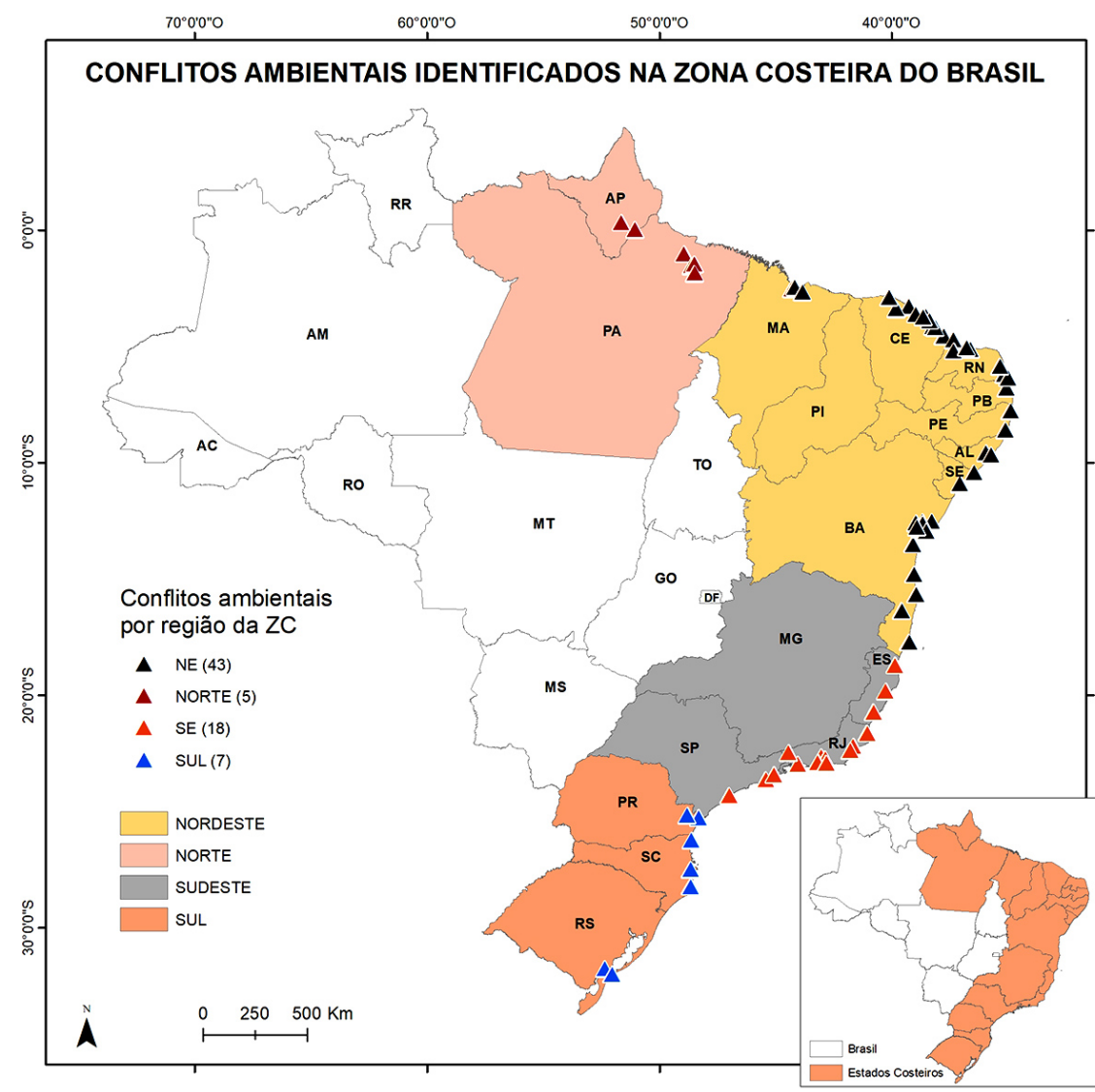

Figura 1 - Estados que compreendem a zona costeira brasileira e a distribuição dos conflitos ambientais envolvendo pescadores(as) artesanais.

Fonte: Elaborado pelas autoras com base nos dados do "Mapa de Conflitos Ambientais envolvendo Injustiça Ambiental e Saúde no Brasil" (2013). 
A partir do mapa de conflitos da Fiocruz foram analisados 339 conflitos, abrangendo os 17 estados que compõem a costa brasileira. Os estados com maior número de conflitos ambientais foram São Paulo, Rio de Janeiro e Bahia, correspondendo a 41, 37 e 34, respectivamente (Porto; Pacheco \& Leroy, 2013). No recorte envolvendo os conflitos relacionados à zona costeira, considerando os grupos sociais que apresentam a pesca artesanal como meio de subsistência, foram encontrados 73 conflitos ambientais. Nas análises direcionadas, Bahia (15), Ceará (12) e Rio de Janeiro (10) foram os estados com maior destaque (Figura 1).

Os resultados denotam que os grupos sociais da zona costeira, que possuem na pesca artesanal seu principal meio de vida ou parte dele, encontram-se envolvidos em conflitos ambientais que apresentam especificidades. Estas se relacionam principalmente às atividades geradoras de conflitos, aos impactos gerados e aos danos à saúde quando comparados à distribuição dos conflitos ambientais em todo o país, incluindo os demais grupos sociais. De acordo com Vasconcellos, Diegues e Sales (2007), há uma clara situação de injustiça ambiental, em que os pescadores e as comunidades do entorno são os principais atores vítimas de problemas ambientais decorrentes de impactos, ampliando, desse modo, sua vulnerabilidade social.

De acordo com a análise dos dados do mapa de conflitos da Fiocruz e de Porto, Pacheco e Leroy (2013), 33,67\% dos conflitos ambientais correspondem à população indígena, enquanto na pesquisa direcionada o grupo social de maior abrangência no que diz respeito aos conflitos é aquele formado pelos pescadores artesanais $(77,27 \%)$ (Tabela I). Os dados encontrados evidenciam a necessidade de uma maior atenção para os pescadores artesanais e para os conflitos ambientais que implicam na alteração das suas atividades de subsistência. Diante disso, Walter et al. (2018) abordam que esses atores possuem seus modos de vida afetados pelas atividades econômicas hegemônicas, fato que culmina em impossibilidades da manutenção da atividade tradicional. Nesse processo, as autoras situam a importância do planejamento de ações (como Programas de Educação Ambiental) que venham a contribuir para a autonomia e melhora na qualidade de vida desses grupos (Walter et al., 2018).

Tabela I - Participação dos grupos sociais envolvidos nos conflitos ambientais que possuem a pesca artesanal como meio de vida

\begin{tabular}{c|c|c}
\hline Grupo Social & $\begin{array}{c}\text { *Número de Conflitos Ambientais (\%) } \\
\text { (Fiocruz) }\end{array}$ & $\begin{array}{c}\text { *Número de Conflitos Ambientais (\%) } \\
\text { (Análise Direcionada) }\end{array}$ \\
\hline Pescadores(as) artesanais & $14,81 \%$ & $78 \%$ \\
\hline Marisqueiras & $2,02 \%$ & $27 \%$ \\
\hline Caiçaras & $3,03 \%$ & $14 \%$ \\
\hline Ribeirinhos & $13,47 \%$ & $14 \%$ \\
\hline Quilombolas & $21,55 \%$ & $33 \%$ \\
\hline Indígenas & $33,67 \%$ & $21 \%$ \\
\hline
\end{tabular}

* Um mesmo conflito pode recair sobre mais de um grupo, por isso totalizam mais de $100 \%$.

Fonte: elaborado pelas autoras com base nos dados do Mapa de Conflitos Ambientais Envolvendo Injustiça Ambiental e Saúde no Brasil (2013).

As atividades geradoras de injustiça ambiental mais recorrentes, de acordo com o mapa de conflitos da Fiocruz, foram a atuação de entidades governamentais $(52,86 \%)$ e monocultura (33,67\%). Na pesquisa direcionada à pesca artesanal, o destaque ficou para a indústria química e de petróleo/gás $(35,62 \%)$, portos e estaleiros $(32,88 \%)$, turismo $(30,14 \%)$ e atividades pesqueiras e carcinicultura (24,66\%) (Figura 2). 
De acordo com a Figura 2 é possível perceber que há uma maior concentração de conflitos ambientais relacionados às atividades de turismo e pesca industrial e carcinicultura nas regiões Norte e Nordeste do país. Por outro lado, nas regiões Sul e Sudeste, as atividades relacionadas à indústria química e de petróleo/gás e os portos e estaleiros são predominantes.

Figura 2 - Distribuição das principais atividades econômicas geradoras de conflitos ambientais sobre os(as) pescadores(as) artesanais na zona costeira.

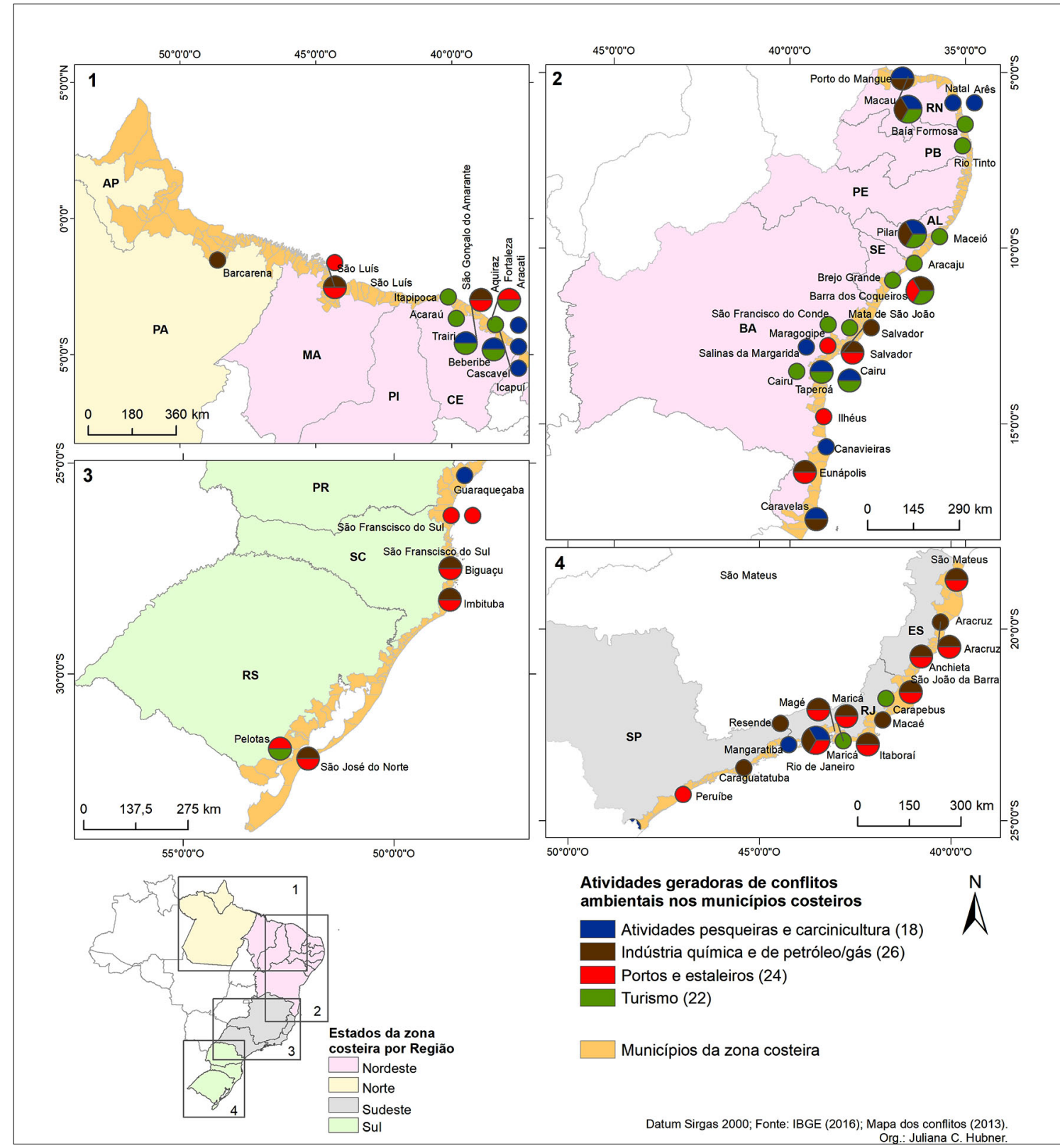

Fonte: Elaborado pelas autoras com base nos dados do "Mapa de Conflitos Ambientais envolvendo Injustiça Ambiental e Saúde no Brasil" (2013).

Em referência às atividades petrolíferas, destaca-se como característica a apropriação dos territórios aquáticos e terrestres. Esses fatores geram, por consequência, a inviabilidade na manutenção e reprodução social dos(as) pescadores(as) artesanais (Passos; Almeida \& Cruz, 2017). Os autores relatam ainda que grandes empreendimentos como 
portos e estaleiros geram enormes impactos à pesca artesanal, como acidentes, perda de equipamentos, perda de áreas de pesca, entre outros, indo ao encontro dos resultados deste trabalho.

Quanto à atividade de turismo, Machado e Gomes (2014) abordam que juntamente com a expansão urbana ocorre o crescimento na atividade turística. Esse fato, consequentemente, ocasiona sobreposição com o espaço ocupado pelos(as) pescadores(as) artesanais. Machado e Gomes (2014) também trazem a reflexão sobre os avanços da exploração da indústria pesqueira sobre as áreas de pesca artesanal, a qual não considera a importância do território para a reprodução dos(as) pescadores(as) artesanais. De acordo com as autoras, tanto o turismo quanto a indústria pesqueira geram entraves à manutenção da atividade de pesca tradicional, fato que reflete o resultado do presente trabalho.

\section{CONSIDERAÇÕES FINAIS}

Os resultados do trabalho evidenciaram 73 conflitos envolvendo pescadores(as) artesanais nos estados que constituem a zona costeira. As principais atividades geradoras desses conflitos se referem à indústria química e de petróleo/gás, portos e estaleiros, turismo e atividade pesqueira e carcinicultura. Estão distribuídas ao longo dos municípios costeiros, com maior concentração de conflitos nas atividades de turismo e pesca industrial e carcinicultura nas regiões Norte e Nordeste do país e da indústria química e de petróleo/ gás e os portos e estaleiros nas regiões Sul e Sudeste.

Os impactos ambientais elencados na pesquisa direcionada em tela apresentaram diferença em relação àqueles encontrados nas análises elaboradas pela Fiocruz a partir do mapa de conflitos. Isso se deve ao fato de que provavelmente os aspectos abordados na primeira têm o direcionamento voltado a uma atividade tradicional específica - a pesca artesanal -, enquanto na segunda, são conflitos ambientais de âmbito mais geral.

Diante dos resultados obtidos nesta pesquisa, é notória a necessidade de dar ênfase aos atores sociais com maior vulnerabilidade, tendo em vista que estes são, em geral, os que possuem pouca visibilidade no que diz respeito às reivindicações e demandas oriundas, muitas vezes, desses conflitos. Isso se dá, principalmente, pelo fato de essas comunidades sofrerem ao receber diretamente os impactos negativos, resultando em alterações no equilíbrio ecológico do ambiente, imprescindível para sua subsistência. Por fim, ressalta-se a importância da continuidade da pesquisa, dando ênfase ao mapeamento de conflitos que envolvam a pesca artesanal, além da relevância quanto ao desenvolvimento de metodologia que atue diretamente no levantamento e na análise de conflitos ambientais associados à atividade pesqueira artesanal.

Agradecimentos - A realização do Projeto de Pesquisa de Avaliação de Impacto Social: uma leitura crítica sobre os impactos de empreendimentos marítimos de exploração e produção de petróleo e gás sobre as comunidades pesqueiras artesanais situadas nos municípios costeiros do Rio de Janeiro é uma medida compensatória estabelecida pelo Termo de Ajustamento de Conduta de responsabilidade da empresa Chevron, conduzido pelo Ministério Público Federal (MPF/RJ), com implementação do Fundo Brasileiro para a Biodiversidade (Funbio). 


\section{REFERÊNCIAS BIBLIOGRÁFICAS}

Acselrad, H. (org.). Conflitos ambientais no Brasil. Rio de Janeiro: Relume Dumará, 296 p., 2004. Acselrad, H. Disputas cognitivas e exercício da capacidade crítica: o caso dos conflitos ambientais no Brasil. Sociologias, v. 16, n. 35, p. 84-105, 2014.

Acselrad, H.; Herculano, S. \& Pádua, J.A. (orgs.). Justiça ambiental e cidadania. Rio de Janeiro: Relume Dumará, 303 p., 2004.

Brasil. Comissão Internacional para os Recursos do Mar - CIRM. Resolução no 005, de 3 de dezembro de 1997. Aprova o Plano Nacional de Gerenciamento Costeiro II (PNGC II). Brasília, 1997.

Cruz, B.O. \& Leoncio, R.C.C. Metrópole do Rio de Janeiro: a condição de trabalho do pescador artesanal na Baía de Guanabara, p. 1-13, in II Seminário Nacional Espaços Costeiros, Bahia, 2013.

Fundação Oswaldo Cruz. Mapa de conflitos envolvendo injustiça ambiental e saúde no Brasil (2018). Disponível em: https:/ / bit.ly/2RMtBwu. Acesso em: 31 maio 2018.

IBGE. Instituto Brasileiro de Geografia e Estatística. Censo Demográfico. 2010. Disponível em: https:/ / censo2010.ibge.gov.br/resultados.html. Acesso em: 16 fev. 2020.

IBGE. Instituto Brasileiro de Geografia e Estatística. Mapas. 2016. Disponível em: https:/ / mapas.ibge.gov.br/bases-e-referenciais/arquivos-raster.html. Acesso em: 16 maio 2017.

Pirajá Júnior, C.M. A zona costeira brasileira como área de proteção às tartarugas marinhas. Rev. El. Dir.e Pol., v. 2, n. 3, p. 291-309, 2007.

Machado, C.B.G. \& Gomes, M.F.V.B. Territorialidade e os conflitos da pesca artesanal na Colônia Z4 - Barra Velha/SC. Bol. Geogr., Maringá, v. 32, n. 3, p. 170-187, 2014.

Ministério do Meio Ambiente. Gerenciamento costeiro no Brasil. Sítio eletrônico do Ministério do Meio Ambiente, 2020. Disponível em: http://www.mma.gov.br/gestao-territorial/ gerenciamento-costeiro. Acesso em: 17 fev. 2020.

Passos, W.S.; Almeida, E.T.V. \& Cruz, J.L.V. Os impactos dos grandes projetos sobre as comunidades atingidas: o caso do Norte Fluminense, p. 1-15, in Encontro Nacional da Associação Nacional de Pós-Graduação e Pesquisa em Planejamento Urbano e Regional, p. 17, São Paulo, 2017.

Porto, M.F.; Pacheco, T. \& Leroy, J. Injustiça ambiental e saúde no Brasil: o mapa de conflitos. Rio de Janeiro: Editora Fiocruz, 306 p., 2013.

Tomáz, A.F. \& Santos, G. Conflitos socioambientais e violação de direitos humanos em comunidades tradicionais pesqueiras no Brasil. Conselho Pastoral dos Pescadores - CPP, 104 p., Brasília, 2016.

Vasconcelos, M.; Diegues, A.C.S. \& Sales, R.R. Limites e possibilidades na gestão da pesca artesanal costeira, p. 15-83, in Costa, A.L. (org.). Nas redes da pesca artesanal. Brasília: Ibama, MMA, 2007.

Walter, T. \& Anello, L.F.S. A educação ambiental enquanto medida mitigadora e compensatória: uma reflexão sobre os conceitos intrínsecos na relação com o Licenciamento Ambiental de Petróleo e Gás tendo a pesca artesanal como contexto. Revista Ambiente $\mathcal{E}$ Educação, Rio Grande, v. 17, n. 1, p. 73-98, 2012. 
Walter, T.; Umpierre, M.B.; Verly, J.F. \& Longaray, A.S. Educação no processo de gestão ambiental: uma leitura sobre os(as) pescadores(as) artesanais enquanto sujeitos do processo educativo, p. 714-726, in Anais do IX Encontro e Diálogos com a Educação Ambiental - EDEA: Educação Ambiental como Espaço de Resistência. Rio Grande/RS: Editora FURG, 761 p., 2018.

Walter, T.; Trentin, G.; Hubner, J.C.; Longaray, A.S.; Veiga, K.R.; Umpierre, M.B.; Caldasso, L.P.; Fischer, J. \& Takahashi, N.F. Conflitos ambientais envolvendo pescadores(as) artesanais na zona costeira, p. 75-109, in Martínez, S.A. \& Hellebrandt, L. (orgs.). Mulheres na atividade pesqueira no Brasil. Campos dos Goytacazes: EDUENF, 382 p., 2019. 